\title{
Elemental characterization of the airborne pollen surface using Electron Probe Microanalysis (EPMA)
}

\author{
Laura Duque $^{\mathrm{a}}$, Fernanda Guimarães ${ }^{\mathrm{b}}$, Helena Ribeiro ${ }^{\mathrm{a}}$, Raquel Sousa ${ }^{\mathrm{a}}$, Ilda Abreu ${ }^{\mathrm{a}, \mathrm{c}, *}$ \\ ${ }^{a}$ Grupo do Ambiente do Centro de Geologia, Universidade do Porto, Portugal \\ ${ }^{\mathrm{b}}$ Laboratório Nacional de Energia e Geologia, S. Mamede de Infesta, Portugal \\ ${ }^{\mathrm{C}}$ Departamento de Biologia, Faculdade de Ciências, Universidade do Porto, Portugal
}

\section{H I G H L I G H T S}

- The elemental composition of the pollen wall differs among plant genera.

- When airborne, the elemental composition of the pollen surface is modified.

- The amounts of $\mathrm{Na}, \mathrm{Cl}, \mathrm{Mg}, \mathrm{K}$ and $\mathrm{Si}$ increase when pollen is in the atmosphere.

- Increasing relative humidity leads to increased levels of $\mathrm{Na}, \mathrm{Cl}$ and $\mathrm{Mg}$.

- Pollen grains are able to adsorb and/or absorb other aerosol components.

\section{A R T I C L E I N F O}

\section{Article history:}

Received 24 January 2013

Received in revised form

12 April 2013

Accepted 15 April 2013

\section{Keywords:}

EPMA

Pollen wall

Elemental characterization

Atmospheric pollution

Aerosol components

Airborne pollen

\begin{abstract}
A B S T R A C T
Recent worldwide increase in pollinoses has been attributed to the synergy between pollen and pollutants. We used EPMA for the elemental characterization of the airborne pollen surface in order to find out what occurs to the wall of pollen grains when they are together with other atmospheric pollutants. Analyses were performed both to airborne pollen and to pollen that was collected from Acer spp., Platanus spp. and Pinus spp. trees. Airborne samples were assembled using a Hirst-type volumetric spore sampler set in the coastal city of Porto, Portugal. Airborne pollen samples showed major elemental differences when compared to the control pollen sample of the same species, namely in the amounts of $\mathrm{Cl}, \mathrm{Na}$ and $\mathrm{Mg}$, which very significantly increased on airborne samples, revealing an important influence of the ocean. Mineral dust also contributed to modify the pollen surface, by increasing Si contents on Acer spp. and Platanus spp. airborne pollen. Our results revealed consistent positive effects of the relative humidity and the precipitation in the increase of $\mathrm{Cl}, \mathrm{Na}$ and $\mathrm{Mg}$ relative amounts on the pollen surface. This study shows that pollen grains have the ability to adsorb and/or absorb other materials, which may contribute to enhance pollen's harmful effects on people's health.
\end{abstract}

(c) 2013 Elsevier Ltd. All rights reserved.

\section{Introduction}

Pollen grains are male reproductive structures of higher plants. Wind and other abiotic and biotic agents transport pollen from the anthers to the stigma of the same flower or of a different flower of the same species, enabling sexual reproduction. Wind pollinated plants release pollen into the atmosphere during the plant pollination season. Thus, pollen becomes part of the atmospheric aerosol, existing in suspension with other particles (Colls, 2002), which enables it to enter people's airways. In addition to being a

\footnotetext{
* Corresponding author. Departamento de Biologia, FCUP, Rua do Campo Alegre s/n, 4169-007 Porto, Portugal. Tel.: +351 220402775.

E-mail address: ianoronh@fc.up.pt (I. Abreu).
}

seasonal air pollutant, the presence and amount of pollen grains in the atmosphere depends on such factors as: meteorology (temperature, precipitation, humidity, wind, etc), biology (physiological state of plants, plant distribution, etc) and topography.

However, pollen is also known because of its effects on human health. It contains proteins that trigger allergic respiratory reactions in many individuals when inhaled (Puc, 2003). But pollen isn't the only component of aerosol that has damaging effects on people's health. It has been demonstrated that air pollution in general has adverse effects on humans. The risk for cardiovascular problems (Scapellato and Lotti, 2007), respiratory symptoms and diseases (D’Amato, 2011; Penttinen et al., 2006), lung cancer (Demetriou et al., 2012) and mortality (Jerrett et al., 2009) are significantly exacerbated when air pollution in general, or one particular pollution component, increases. Moreover, pollinoses are 